\section{Can computers read your mind?}

Erik Ensrud, MD
Being fully awake and alert but trapped in a body that is unable to move or speak must be very frightening and frustrating. This is often the situation for patients in the late stages of Lou Gehrig's disease (amyotrophic lateral sclerosis or ALS). Now there is new hope that computers may be able to help these patients communicate by, in a way, "reading their minds."

In this issue of Neurology, Kübler et al. ${ }^{1}$ reported that four people with severe ALS were able to learn to direct a computer screen cursor by modifying their brain waves through the use of a braincomputer interface $(\mathrm{BCl})$. ALS is a rare disease that affects the ability to move and communicate as we usually do with speaking, gestures, and writing. More information about ALS can be found on the next page.

\section{What is a BCI?}

$\mathrm{A} \mathrm{BCl}$ is a computer device that helps a person operate a computer by using systems that measure brain waves rather than using his or her hands. Changes in the brain waves are then converted to systems such as a simple wordprocessing program.

\section{What are brain waves?}

Brain waves are patterns of electrical brain activity. Brain cells can communicate with each other by electricity and chemicals called neurotransmitters. The electrical activity of the brain is measured by a test called the electroencephalogram (EEG). For this test, tiny metal discs called electrodes are pain- lessly stuck to the scalp with gel or paste. These electrodes can pick up the electrical impulses of the brain, which pass through the skull. This electrical activity is very weak, so the signal is then enlarged in strength by an EEG machine. The EEG machine can then display the recorded brain electrical activity on a computer screen or paper tracing. Brain waves measured by EEG do not represent a particular thought or movement, but rather represent a summary of brain electrical activity at a recording point on the scalp. You could compare an EEG recording to being able to look at an ocean and identify that there are big or little waves and determine what direction they are coming from, but not being able to pick out one individual wave. Brain waves can be altered by thoughts of planned action (such as thinking of moving a hand), without actually moving the hand itself. Trying to convert the ability to think of a movement into actually moving a computer cursor is what this study by Kübler is about.

\section{What did the researchers do?} They worked with four patients with ALS over 3 to 7 months. These patients learned how to use a $\mathrm{BCl}$ to adjust a type of brain wave to control a computer screen cursor (like most people move with the use of a computer mouse). The patients trained their minds by essentially imagining moving the computer cursor. Electrodes were placed on the scalp above the region of the brain that governs voluntary movement and were able to pick up brain waves that changed in size depending on whether or not the patient was imagining the movement. This study used a type of brain wave that was different from what has been tried before with ALS patients and which allowed faster movement of the cursor.

\section{Why is this study important? Enabling these patients to control a computer cursor may allow them to communicate by moving the cursor to a specific word or phrase on a computer screen. It also could allow patients to do other actions than communicating, such as turn- ing lights off and on or even using a thought-controlled wheelchair. It is exciting that these patients may be able to communicate more ef- fectively in the future. $\mathrm{BCls}$ are an active area of research and even more promising developments are expected in the coming years.}

\section{Who would need or want to use a BCI?}

There are many diseases of the nervous system that affect the ability to move and result in communication difficulties for these patients. These include ALS, spinal cord injury, and strokes in certain areas of the brain. Patients with movement problems from these diseases may be able to benefit from braincomputer interfaces. Having the ability to think but not communicate can create a difficult and frustrating situation for these patients, their caregivers, and their family and friends. This study shows promising results that a new method of enabling these patients to communicate may be possible. 


\section{What is ALS?}

ALS is best known as Lou Gehrig's disease. It is also called motor neuron disease because it affects nerve cells (called neurons) in the brain and spinal cord that govern strength and movement. Over time, the arms and legs become progressively weaker, eventually leading to total paralysis. The disease also affects nerves involved in speaking, swallowing, and breathing. Therefore, patients will eventually become unable to eat or even breathe on their own. Despite these devastating problems with paralysis, most patients will not have major problems with their thinking or memory. However, communication does become a problem because patients eventually will not be able to speak, gesture, or write. For $80 \%$ of people, weakness tends to progress, causing death in 3 to 5 years. Some of the signs and symptoms of ALS are shown in the bulleted list below.

ALS can strike anyone and at any age, but it generally occurs between the ages of 40 and 70 years. An estimated 5,000 people in the United States are diagnosed with ALS each year.

\section{What are the symptoms?}

ALS usually comes on slowly. The first signs are often arm or leg weakness, problems with speaking or swallowing, muscle twitches or cramps, loss of muscle mass, tight or stiff muscles, and fatigue. Some people laugh or cry more easily without apparent reason. In time, all muscles involved with voluntary movement are affected. ALS does not affect involuntary muscles, such as those that control the heart and the digestive system.

\section{How is ALS diagnosed?}

There is no specific test to diagnose ALS. Several tests, including nerve conduction studies and electromyogram (EMG), measure how well the nerves are working. Excluding other causes of muscle weakness is important.

\section{What causes ALS?}

The cause of ALS is not known. Five to $10 \%$ of those with ALS have a family history of the disorder and show a genetic pattern. In this form, offspring have approximately a $50 \%$ chance of developing ALS. This is called familial ALS.

\section{What are the treatments?}

There is no known cure for ALS, but research is promising. The drug riluzole modestly increases survival time. Other potential treatments are being studied.

The primary treatment is managing ALS symptoms. People with ALS need to take an active role in planning and carrying out their treatment. Ideally, physical, occupational, speech, respiratory, and nutrition therapy will be involved. A neurologist is the doctor best qualified to work with the treatment team.

Learning you have ALS can lead to feelings of anxiety, fear, and depression. It is not unusual to feel overwhelmed or numb. Your family and friends may share these feelings. Your doctor, therapists, and support groups can help you, your family, and your friends through the difficult times ahead. It is important to talk about the diagnosis and what it means to you.

\section{Common symptoms of ALS include:}

Weakness in the hands and feet Trouble walking

Trouble breathing or lying flat

Changes in voice

Trouble chewing

Trouble swallowing

Pain in joints

Depression

Fatigue

Muscle cramps

Muscle twitches

Problems sleeping

Anxiety

Constipation

\section{For more information}

American Academy of Neurology

Foundation

www.thebrainmatters.org

ALS Association

www.alsa.org

International Alliance of ALS/MND

Associations

www.alsmndalliance.org

\section{Reference}

1. Kübler A, Nijboer F, Mellinger J, et al. Patients with ALS can use sensorimotor rhythms to operate a brain-computer interface. Neurology 2005;64:1775-1777. 


\title{
Neurology
}

\author{
Can computers read your mind? \\ Erik Ensrud \\ Neurology 2005;64;E30-E31 \\ DOI 10.1212/WNL.64.10.E30
}

\section{This information is current as of May 23, 2005}

Updated Information \& Services

References

Permissions \& Licensing

Reprints including high resolution figures, can be found at: http://n.neurology.org/content/64/10/E30.full

This article cites 1 articles, 1 of which you can access for free at: http://n.neurology.org/content/64/10/E30.full\#ref-list-1

Information about reproducing this article in parts (figures,tables) or in its entirety can be found online at:

http://www.neurology.org/about/about_the_journal\#permissions

Information about ordering reprints can be found online: http://n.neurology.org/subscribers/advertise

Neurology ${ }^{\circledR}$ is the official journal of the American Academy of Neurology. Published continuously since 1951, it is now a weekly with 48 issues per year. Copyright . All rights reserved. Print ISSN: 0028-3878. Online ISSN: 1526-632X.

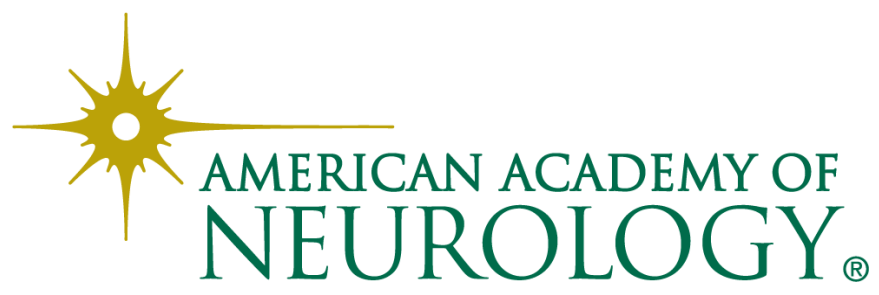

